DOI: 10.20472/IAC.2017.031.012

\author{
DEBRA BOURDEAU \\ Embry-Riddle Aeronautical University--Worldwide, United States
}

\title{
PLATO IN SINGAPORE: A CASE FOR GLOBALIZING ETHICS COURSES
}

\begin{abstract}
:
This paper discusses my experience as an American instructor teaching a Values and Ethics course in Singapore. This course is required of all students in our university, which is a distributed-campus model with over 120 teaching sites, including our Asia campus. Having developed this course for online delivery for all of our instructors, I was aware of the Western focus of its textbook and its worldview. Similarly, the course itself is built upon Western teaching practices. Both realities produced a fascinating experience when I taught the course to approximately 60 undergraduate Singaporean students in a condensed nine-week format in 2015. The almost-fully Western view, based heavily on Judeo-Christian values and the philosophy of Aristotle, Plato, Descartes and Kant, proved to be a myopic way to approach the course. Blending Eastern concepts such as collectivism with Western ideals such as individualism, and the Western focus on reason with Buddhist understandings of cause/effect relationships, added depth to the student experience in the course and provided me with new levels of insight as an instructor. Additionally, the course demands significant student participation and collaboration, with the instructor often becoming more of a facilitator in the course. Singaporean students commented that this was a new way of learning for them, removing the layers of authority between student and teacher and increasing their confidence in their ability to speak articulately on course concepts. Finally, the class demands the application of various ethical frameworks to current issues, compelling students to consider contemporary world problems through the lens of formal philosophical thought. Their topics of choice provided an intriguing contrast to American students' selections for that same set of assignments. Ultimately, increasing globalization demands an internationalized curriculum that is not overly dependent on the traditions of any one specific culture. My experience in this course provides a case study of "accidental" internationalization that could, ideally, lead to some permanent changes in how such courses can be taught to students worldwide.
\end{abstract}

\section{Keywords:}

teaching, humanities, values and ethics

full paper do proceedings. nahraje do 11.6 . 